\title{
Analysis on the Ethics of Modern Network Technology from the Perspective of Marxism Ethical Thought
}

\author{
Zhiyuan $\mathrm{HU}^{1,}$ a , Dexiang Zhou ${ }^{2, \mathrm{~b}}$ \\ ${ }^{1}$ School of Marxism, Hohai University, Nanjing 210098, China \\ ${ }^{2}$ School of Marxism, Hohai University, Nanjing 210098, China \\ ahubin0072@126.com, ${ }^{b}$ zhoudexiang7428@sina.com
}

Keywords: Network ethics; Network Technology; value; Marxism Ethical Thought

\begin{abstract}
The network has provided a broad space for human activities today. In combination with modern network technology frontier and the demand of the society, the network technology is influencing and changing of the modern society with its enormous power. However, the network technology brings the benefits for the mankind; it also brings a lot of ethics conflict. Therefore, it is particularly necessary to strengthen the network ethical construction and enhance the whole society network civilization consciousness so as to cultivate the network subject spirit and to promote the construction of the network culture from the perspective of Marxism ethical thought. We can purify network environment and create a harmonious network space under the guidance of scientific ethical thought.
\end{abstract}

\section{Instruction}

The rapid development of modern network technology becomes the primary power of the economic development, the social progress and the reform of the human ethics. At the same time, it also brings the history of the world into an adjustment period. When people truly enjoy the great convenience for the network technology bringing, it also caused the ethical problems, which people pay too much attention. The network has provided a broad space for human activities today. In combination with modern network technology frontier and the demand of the society, the network technology is influencing and changing of the modern society with its enormous power. However, the network technology brings the benefits for the mankind; it also brings a lot of ethics conflict. Therefore, it is particularly necessary to strengthen the network ethical construction and enhance the whole society network civilization consciousness so as to cultivate the network subject spirit and to promote the construction of the network culture from the perspective of Marxism ethical thought. We can purify network environment and create a harmonious network space under the guidance of scientific ethical thought.

\section{The moral conflict of the modern network technology}

"In the face of the rapid extension of the information highway and most of the Internet, we have a catch all in one draft feeling. Everywhere there is network, each time has a network and everyone has the network in the whole world." [1] This is a network revolution of the new information time. It has brought to the human life and ethics for the convenience, at the same time it also produced a series of conflicts.

\subsection{Conflict between cyberspace particularity and existing moral environment}

Cyberspace has created a new environment for human life, which has challenged the original moral experience and values. The network technology has brought the hidden, non-binding, expand and virtual characteristic, that would cause the split personality, leading communication to lots of ethical and moral issues such as apathy, ethical crisis of confidence, moral behavior and imbalance. This is because that when we use the network, we must deal with media picture all day, the dependent relationship between people is replaced by the dependent relationship on the network. The exchanges between people become the interaction between man and machine, which turns the 
people relation into the utilitarian, economization, indifference and commercialization, and gradually lose its moral and social concerns finally. Melodic said: "technical civilization not only has created all sorts of methods to overcome the distance of time and space between the people, but also created a powerful separation factors, which make people too isolated without mutual understanding and paranoid, and the contact between the social organizations become increasingly weak"[2]. Especially, the moral crisis of trust in virtual and open network space makes the real world lose the sense of reality, appearing the mistrust between people and impacting the principle of good faith and moral immensely. Once the network subject goes back to the real life, it will also keep a wary of reality, thinking the real world is unreal and unreal. If the Internet users do not transform on time in the social reality and the virtual society, which will aggravate the crisis of confidence the interpersonal communication of the social reality.

Thus, the rational value of network communication technology, shakes people's original humane rationality, target value from time to time and makes people to become "technology fetishism" believers, who bogged inextricably down the virtual space, escaping from real life, ignoring the emotional and social relations and lacking sense of responsibility for society and sense of participation.

\subsection{Clash between network communication and moral psychology mechanism}

Network communication space provides immoral entrants with the green light for the immoral behavior, resulting in weakening the network moral consciousness and the unbalance of moral behavior.

The invasion of personal privacy, intellectual property disputes, hackers and network theft is the best explanation. The reason is that in the network space, people can create their own like role arbitrarily according to their own needs, create virtual ideal self, and seek self-expression online. The interaction object has no any psychological burden, as if with a mask of personality. There is a kind of feeling of psychological indulgence acting recklessly and care for nobody as one pleases. It is not only incline to making personal sense of responsibility and moral decline, the faith and apathetic lose, but also easy to make values distort and to seek nothing but profits, which is not conducive to the stability of interpersonal relationship. At this time, the network has become a promised land to let people do as one pleases freedom. On the other hand, the Internet communication has an equal attitude, that makes the equality of the main body online communication strengthened, but at the same time, the moral communication behavior is weakened, that makes the constrains of network friends' ethics morality loose, which is not only to strengthen the equality between the network friends' communication, also to make the relationship with the larger changeability and complexity.

\subsection{Conflicts between network moral uncertainty and traditional ethical action}

In the network society, there is no unified ethical standard. The different point of view network individual held could easily lead to the prevalence of moral relativism, which will bring cognitive burnout and weak of the ethical judgment. As long as individuals' behavior is in line with their own beliefs, they can not consider whether their behavior destroys traditional morality. The individual is not worth mentioning in the global network of groups as a drop in the bucket. The small feel let people think that their behaviors have no any limit, which contributed to the anarchist ethos so as to weaken the state control of the spiritual realm. The traditional moral principles of collectivism received the challenge and impact from network moral relativism, anarchy. As everyone knows, there is no absolute freedom, for the freedom without restriction will lead to no freedom. However, on the Internet, because there is no unified mechanism of regulation and restriction, the anarchism can attack and diatribe the government as free online, or make personal attacks. Due to the lack of supervision and guidance between information exchanges, there must be spray made by network citizen, as long as a trend of the popular form. The later inadvertently must be coerced to the spray. Therefore, due to absence of independent thinking and creativity today, it's easy to take things as necessary for people. Thus, the essential spiritual territory in the people's brains is easily conquered, making great conflicts with the traditional ethics.

Furthermore, the new broad space is created by network, which will cause a variety of ideas 
interaction. The mainstream ethics is submerged in the personal prayer so as to cause the befuddlement of people's moral choice. If the carrier distance between the individual's behaviors exceeds the moral scope, the traditional ethics existing in the network space can not directly answer a series of new subjects of moral. We can not answer the questions using directly in right and wrong for many of the network behavior because we do not make out new network ethics rules yet. Therefore, there is a moral vacuum for how to choose and choosing what morality.

Toynbee suggested: "the technology goes every step, the strength increases a lot. This power can be used for two aspects of the good and the evil." [3] The human moved forward from fool to civilization and the modern with great encouragement from the slogan: "knowledge is power", but the human are also executing its spirit "euthanasia" quietly in the omnipotence of scientific dream.

\section{The methods of discarding the negative moral effect of network technology}

"The network has become the second living space of human or the first living environment, but from the above analysis shows that the network is bringing great convenience to people, at the same time, it also has made a series of ethical problems of the network with the more wide application of network. Thus, we must create a secure digital environment consciously." [4] Therefore, the focus on the construction of network ethics is not the formulation of the specific law and rules, but the reinforcement of spiritual civilization construction based on the network behavior. Promoting humane education, cultivating network civilization, strengthening the construction of network culture provides the correct orientation for people's communication of network and constructs a harmonious network society.

\subsection{Setting up the ethics moral concept of network trust responsibility}

The development of modern technology has put forward new moral requirements of network culture, these of the key point lies in human, who use the network tool. Therefore, the network subjects must use the civilized language and operation so that they can reflect, alter, improve and develop their own through the application of network technology. Giving full consideration to the issue of network security, the network subjects must foster the integrity, justice, equal civilization style of the network and harmony network space. Network civilization requires establishing moral philosophy of mutual respect in the Internet, inhibiting the opposite behavior derivative, establish the optimization and safe civilization consciousness of the network. One of the most important hardware is constantly the renovation of network technology, which can protect the "firewall" by setting the internal information technology and enhance the technology of sewage pollution and decontamination ability, so as to control bad information of the mental garbage such as pornography, violence virus which has adverse effect on social development. Another important factor is the online software: a person's behavior must be restricted. People must regulate their own behavior consciously to improve their own network civilization level of consciousness. Meanwhile, people must respect others rights and freedom, including privacy, copyright, right of reputation and so on, so that they can carry actively out the maintenance of network credit responsibility.

\subsection{Achieving self-discipline of the network subject}

In the network world, the real life of people gets perfect reality through conscious technical activities, which needs Infiltrating technology consciousness to the life Consciousness. This requires that we should set up the network main body spirit consciousness through the humanities education. The education of human value and meaning of life is promoted to the spiritual realm education. We should purify the human mind and enhance people's cultural quality and ideological level through the care of personal development, human progress and the fate education so as to make us become the people with the broad mind, spirit harmony, taste noble, healthy personality, so as to make humanistic spirit become the spiritual pillar of the network society throughout the development of the network technology, which can not be missing.

Marx once pointed out: the basis of morals is human self-discipline. The personal morality requirements can be said to be an inevitable trend in the information age of the development of ethics. The self-discipline contained in humanistic spirit requires that every network subject should 
comply with consciously internalized ethics and pay close attention to the human spirit home and moral character molding.

\subsection{Constructing the ethics network system of Chinese Characteristics}

In twenty-first Century, with the globalization trend developing increasingly, the network technology is also developing and changing constantly. Thus, keeping pace with the times, we should strengthen exchanges and cooperation with all the countries in the world, network technology. On the base of the foreign successful experience of other countries for reference, we have strengthened the construction of network culture and standardized the development of network ethics, which provide powerful guarantee for the construction of socialist spiritual civilization. This requires strengthening the constraints of ethical network communication and international cooperation of the network standard so as to eliminate effectively the information exchange inequality against the information monopoly and hegemony. Therefore, "we combine the content of network moral education with Chinese reality so as to form an ideological system of network moral education with Chinese characteristics. At the same time, we must strengthen the ethical culture construction with Chinese characteristics resisting the erosion of western decadent ideas. We must pay more attention to the construction and management of the network culture from the three representatives, especially the direction of advanced culture, so that we can occupy the network position with scientific, popular, folk culture and guide the development of socialist culture "[5]. Only in this way, can we improve and develop the socialist moral system in China and raise public identity of the network ethics so as to promote the construction of socialist spiritual civilization.

\section{Conclusion}

In short, the construction of network ethics is advancing inevitably with the Internet development and the construction of network ethics is also perfecting inevitably with the improvement of network subjects quality. We must grasp the opportunity of people growing concerns about network ethics to strengthen the construction of network ethics, so that we can share the convenience and benefits which the network has brought us in a network society full of the moral ethics order.

\section{Acknowledgements}

This work was financially supported by the scientific research innovation project in Jiangsu province in 2012 (CXZZ12_0222).

\section{References}

[1] Li Zhengjun. Preliminary Study of Contemporary College Students on Network Ethics Problem [J]. Lingling College Journal Eeducstion Science). 2004, (6).

[2] Malkovich. About Argument of Marx Socialism Humanitarian [M]. Dai Maochang, Trans. Shanghai: Shanghai press, 1981:28.

[3] Toynbee, Daisaku Ikeda. The Prospect on the Twenty-first Century [M]. Beijing: International Culture Publishing Corporation. 1985:388.

[4] Nigeluo • Ponti. Being digital [M]. Fan Haiyan, trans. Haikou: Hainan Press, 1998:14.

[5] Ke Changqin, Shen Haibo. The Network Ethics Problem and Countermeasure [J]. Hubei Education Institute Journal. 2005, (3).

[6] Complete Works of Marx Engels: Volume First [M]. Beijing: People's Publishing House. 1995. 